\title{
Predictors of clinical or cerebral lesion progression in adult moyamoya angiopathy
}

Dominique Hervé, MD, Nathanaelle Ibos-Augé, MD, Lionel Calvière, MD, Christina Rogan, MSc, Marc Antoine Labeyrie, MD, Jean Pierre Guichard, MD, Ophélia Godin, PhD, Manoelle Kossorotoff, MD, PhD, Marie Odile Habert, MD, Elisabeth Tournier Lasserve, MD, Sylvie Chevret, MD, PhD, and

Hugues Chabriat, MD, PhD

Neurology ${ }^{\circledR}$ 2019;93:e388-e397. doi:10.1212/WNL.0000000000007819

\section{Abstract}

\section{Objective}

To identify independent predictors of clinical or cerebral lesion progression in a large sample of adult patients with moyamoya angiopathy (MMA) prior to decisions regarding revascularization surgery.

\section{Methods}

Ninety participants (median age, 37.5 years) were assessed at baseline and followed for a median time of 42.8 months. Incident ischemic and hemorrhagic strokes, death, as well as any incident ischemic and hemorrhagic lesions on MRI were recorded. Multiple demographic, clinical, and cerebral imaging measures at baseline were considered as potential predictors of clinical or cerebral tissue change at follow-up. Data were analyzed based on the Andersen-Gill counting process model, followed by internal validation of the prediction model.

\section{Results}

Among multiple potential predictive measures considered in the analysis, Asian origin, a history of TIAs, and a reduction in hemodynamic reserve, as detected by imaging, were found to be significantly associated with an increased risk of combined clinical and imaging events. While the model estimated the risk of clinical or cerebral lesion progression to be approximately $0.5 \%$ per year when none of these factors was present, this risk exceeded $20 \%$ per year when all factors were present.

\section{Conclusion}

A simple combination of demographic, clinical, and cerebral perfusion imaging measures may aid in predicting the risk of incident stroke and cerebral lesion progression in adult patients with MMA. These results may help to improve therapeutic decisions and aid in the design of future trials in adults with this rare condition.

\author{
Correspondence \\ Dr. Hervé \\ dominique.herve@aphp.fr \\ or Dr. Chabriat \\ hugues.chabriat@aphp.fr
}

\section{MORE ONLINE}

- CME Course

NPub.org/cmelist

From the Referral Center for Rare Vascular Diseases of the Brain and Retina (CERVCO), Department of Neurology and DHU NeuroVasc (D.H., N.I.-A., C.R., O.G., H.C.), Department of Neuroradiology (M.A.L., J.P.G.), and Laboratoire de Génétique Moléculaire (E.T.L.), Hopital Lariboisiére, Department of Nuclear Medicine, Hopital Salpêtrière (M.O.H.), and Service de Biostatistique et Information Médicale, Hôpital Saint Louis (S.C.), Assistance Publique des Hôpitaux de Paris; INSERM U 1161 (D.H., E.T.L., H.C.) and UMR 1153 INSERM (S.C.), Université Paris 7 Diderot (E.T.L., H.C.), Sorbonne Paris Cité; Unité Neurovasculaire (L.C.), Hôpital Pierre-Paul-Riquet, Toulouse; Centre National de Référence de I'AVC de l'Enfant, Hôpital Universitaire Necker-Enfants Malades (M.K.), AP-HP; Sorbonne Paris Cité, Paris; and ECSTRA Team (Épidémiologie Clinique et Statistiques pour la Recherche en Santé) (S.C.), Paris, France.

Go to Neurology.org/N for full disclosures. Funding information and disclosures deemed relevant by the authors, if any, are provided at the end of the article. 


\section{Glossary}

AIC = Akaike information criterion; ASOL $=$ arterial steno-occlusive lesions; AUC $=$ area under the time-dependent receiver operator characteristic curve; $\mathbf{C B F}$ = cerebral blood flow; FLAIR = fluid-attenuated inversion recovery; $\mathbf{C V R}$ = cerebrovascular reserve; $\mathrm{HMPAO}=$ hexamethylpropyleneaminoxime; $\mathrm{IQR}=$ interquartile range; $\mathrm{MICE}=$ multiple imputations with chained equations; $\mathbf{M M A}=$ moyamoya angiopathy; $\mathbf{M M D}=$ moyamoya disease $; \mathbf{M M S}=$ moyamoya syndrome $\mathbf{m R S}=$ modified Rankin Scale.

Moyamoya angiopathy (MMA) is a rare cerebrovascular disorder characterized by the progressive stenosis of supraclinoid internal carotid arteries and their branches, in association with a network of basal collaterals. ${ }^{1}$

Various surgical revascularization techniques are widely applied in children to improve cerebral perfusion and prevent ischemic or hemorrhagic consequences of MMA. ${ }^{2-11}$ Surgical revascularization is also proposed for adult patients. ${ }^{12}$ However, little is known about the natural history of MMA in adult patients, although limited data suggest that progression of the disease might be more indolent in adults than in children. ${ }^{13} \mathrm{In}$ previous longitudinal studies including adult nonoperated cases, clinical and imaging outcomes were not standardized, the duration of follow-up was limited, or the sample size was small. ${ }^{14-19}$ In addition, therapeutic decisions differ substantially among centers according to the local physician's expertise, experience in revascularization surgery, and explorations used before decision-making. Additional prospective studies are urgently needed to define predictive models that could be used to improve treatment decisions in adults with MMA.

In the present cohort study, we aimed to identify independent predictors of clinical or cerebral lesion progression in a large sample of adult individuals with MMA prior to decisions regarding revascularization surgery.

\section{Methods}

This article was prepared according to the Strengthening the Reporting of Observational Studies in Epidemiology (STROBE) statements. ${ }^{20}$

\section{Study design}

Among all possible MMA cases referred to the French national referral center for rare vascular diseases of the brain and retina (cervco.fr) between 1999 and 2017, all individuals who satisfied the following criteria were included in the prospective observational study: (1) MMA diagnosed according to the most current definition ${ }^{21}$ and confirmed by both a vascular neurologist (D.H.) and neuroradiologist (M.A.L.), (2) age greater than 16 years, and (3) no history of revascularization surgery and no surgical decision planned at the time of inclusion.

\section{Standard protocol approvals, registrations, and patient consents}

Informed consent was obtained for collecting imaging, demographic, and clinical data from each participant, and the protocol study was approved by an independent ethics committee (Ethics Evaluation Committee of INSERM, reference 17-388).

\section{Data collection}

All data were collected from different sources at the individual level and during each visit to the referral center. Data were transmitted electronically according to the best good clinical practice standards using a dedicated electronic case report form. ${ }^{22} \mathrm{~A}$ follow-up clinical evaluation was offered to all participants included in the study on a yearly basis at the site of the national referral center. However, follow-up visits to the center were not considered mandatory if it was possible for the patient to see a general practitioner or local neurologist regularly. Data obtained from the MMA cohort were ultimately included in the analysis only when baseline data were followed by at least a second visit with a complete evaluation at the referral center more than 1 year after inclusion.

\section{Collection of baseline and follow-up data}

Demographic data (age, sex, ethnic origin, and years of education) and vascular risk factors (previous diagnosis of hypertension with use of an antihypertensive treatment, systolic and diastolic blood pressure, diabetes mellitus, hypercholesterolemia, smoking, and alcohol use) were obtained at study entry. A history of TIAs, defined as focal symptoms lasting $<24$ hours (presumably of vascular origin); stroke, defined as rapidly evolving focal symptoms lasting $\geq 24$ hours associated with ischemic or hemorrhagic lesions on CT scan or MRI; and seizures or migraine with or without aura were systematically evaluated. Time from the most recent stroke or TIA event to enrollment was recorded, as was the time of first neurologic focal deficit. Disability was also assessed using the modified Rankin Scale (mRS). MMA cases were classified in 2 types, as moyamoya syndrome (MMS) when MMA was associated with specific acquired or genetic conditions and as moyamoya disease (MMD) when MMA was isolated. All patients also received a baseline cerebral MRI that included diffusionweighted, fluid-attenuated inversion recovery (FLAIR), and $\mathrm{T} 2{ }^{*}$-weighted (gradient echo) images. Images were analyzed during dedicated sessions by a vascular neurologist and a neuroradiologist blinded to the clinical status. Only findings recognized by consensus were considered for analysis. The following measures were systematically collected using all imaging data available: (1) presence and location of all potential ischemic or hemorrhagic lesions (recent or old infarcts, subarachnoid hemorrhages, intraparenchymal hemorrhages, 
and microbleeds); (2) presence of hyperintense vessels on FLAIR; (3) location of intracranial arterial narrowing or occlusion; (4) presence of moyamoya collateral vessels; (5) presence of transdural anastomosis; (6) narrowing score, corresponding to the sum of arteries (one point for each internal carotid artery, anterior cerebral artery, middle cerebral artery, and posterior cerebral artery), with either stenosis or occlusion (ranging from 0 to 8); (7) Suzuki score obtained from baseline conventional angiography data.

For patients within convenient commuting distance from the referral center, basal and acetazolamide brain perfusion SPECT with ${ }^{99 \mathrm{~m}}$ Tc-hexamethylpropyleneaminoxime (HMPAO) images, in addition to MRI, were also obtained a few days after the baseline visit, where possible, to evaluate cerebral perfusion and hemodynamic reserve. Two SPECT acquisitions, baseline and post-acetazolamide, were performed with a 48hour interval. For both acquisitions, participants had an IV line while they rested in a quiet and dimly lit room 10 minutes prior to, during, and at least 5 minutes postinjection of ${ }^{99} \mathrm{~m}$ Tc-HMPAO. For the evaluation of hemodynamic reserve, acetazolamide $(1 \mathrm{~g})$ was slowly administrated via the catheter, 20 minutes before the injection of the radiotracer. The reconstructed slices of both scans were then coregistered, and displayed together. Images were intensity scaled with the cerebellum as reference, namely that for each scan, the maximum value in the cerebellum corresponded to the maximum of the color scale, allowing a visual comparison between basal and post-acetazolamide images. When present, cerebral hypoperfusion at the cortical level was considered severe (level identical to or below white matter cerebral blood flow [CBF] values, more than 50\% decrease), moderate (corresponding to a $30 \%-50 \%$ decrease), or mild (close to CBF values in non-affected areas) in the different cerebral lobes. Thereafter, each hypoperfused area on basal SPECT images was assessed based on all MRI parenchymal images available and considered to be related to preexisting cerebral damage (atrophy or obvious infarction or hemorrhage), remote diaschisis secondary to a large cortical lesion, or the direct result of arterial steno-occlusive lesions (ASOL). Alterations in cerebrovascular reserve (CVR) were assessed qualitatively by comparing basal and acetazolamide SPECT images. Intraobserver reproducibility was good $(\kappa=0.60)$ for detecting regional hypoperfusion related to ASOL, and excellent $(\kappa=$ 0.88) for recognizing regionally decreased CVR. Interobserver reproducibility was good for both of these measures ( $\kappa=0.76$ and 0.64 , respectively).

During follow-up, a thorough interview of each patient and an analysis of all available medical records were used to collect any incident clinical events, particularly any TIAs or incident strokes. Disability was also assessed using the mRS score. MRI data obtained at baseline and at the last visit to the referral center were also compared to identify any new focal ischemic or hemorrhagic cerebral lesions. The presence of such incidental lesions was confirmed by consensus of 2 different observers. In cases where a decision to perform cerebral revascularization was made during follow-up, all data obtained from the date of surgery were censored.

\section{Outcomes}

As previously reported in other longitudinal studies of rare cerebrovascular disorders, ${ }^{23}$ outcome was defined by all clinical and imaging manifestations at the cerebral tissue level suggestive of disease progression; both ischemic and hemorrhagic stroke, death, and any incidental ischemic or hemorrhagic lesions observed during follow-up were considered. The time to occurrence of each event was also defined as a secondary outcome.

\section{Statistical analysis}

To obtain the largest sample size of individuals with this rare condition, we considered all MMA patients referred to the center for the present study.

Summary statistics, namely percentages and median values with interquartile ranges (IQRs), were used unless otherwise specified.

The Andersen-Gill counting process model was used for analyzing follow-up data since this model can handle recurrent events and can take into account the correlated, but unspecified, structure of the data. ${ }^{24}$ The following measures collected at the baseline visit were first considered as potential predictors of clinical or cerebral tissue change at follow-up: age at first symptoms; age at baseline; sex; ethnic origin (Asian, European, or African); MMA type (MMS or MMD); bilateral or unilateral steno-occlusive lesions; various vascular risk factors (hypertension, hypercholesterolemia, diabetes mellitus, alcohol consumption, active smoker); a history of TIAs, ischemic stroke, or hemorrhagic stroke; time elapsed since the last TIA and since the last completed stroke; the presence on MRI of any brain infarct, intraparenchymal hemorrhage, or intravascular hyperintensities; arterial narrowing score; Suzuki score; presence of transdural anastomosis on cerebral angiography; presence of regional hypoperfusion related to ASOL; and alterations in CVR based on SPECT data. First, univariate models were fitted such that all covariates previously reported as risk factors in MMA were considered fixed covariates. Multivariate models were then fitted to predictors selected from univariate analyses at the $10 \%$ level (unless the sample included $<10$ patients), segregating demographic, clinical, MRI, angiographic, and SPECT characteristics. Model selection was based on a stepwise procedure, starting with the full model and removing/adding predictors according to the Akaike information criterion (AIC), and after multiple imputations with chained equations (MICE) of missing data, estimates were averaged over 30 datasets.

Internal validation of the prediction models was based on the Somers Dxy rank correlation, a bias-corrected index, conducted using ordinary nonparametric bootstrapping (150 bootstrap samples) and area under the time-dependent 
Table 1 Baseline demographic, angiographic, clinical, MRI, and perfusion measures

\begin{tabular}{|c|c|}
\hline & $\begin{array}{l}\text { No. (\%) or median } \\
\text { (IQR) }\end{array}$ \\
\hline Age at first symptom, y & $32.0(23-43)$ \\
\hline Age at baseline, $y$ & $37.5(29.1-48.7)$ \\
\hline Female & $63(70)$ \\
\hline \multicolumn{2}{|l|}{ Ethnic origin ${ }^{a}$} \\
\hline European & $54(60)$ \\
\hline Asian $^{\mathrm{b}}$ & $12(13)$ \\
\hline African & $20(22)$ \\
\hline \multicolumn{2}{|l|}{ MMA type } \\
\hline MMD & $54(60)$ \\
\hline MMS & $36(40)$ \\
\hline Bilateral & $58(64)$ \\
\hline \multicolumn{2}{|l|}{ Vascular risk factors } \\
\hline Hypertension & $29(32)$ \\
\hline Hypercholesterolemia & $23(26)$ \\
\hline Active smoking & $23(26)$ \\
\hline Diabetes mellitus & $5(6)$ \\
\hline Alcohol consumption & $6(7)$ \\
\hline \multicolumn{2}{|l|}{ Main clinical manifestations } \\
\hline TIAs & $43(48)$ \\
\hline Ischemic stroke & $39(43)$ \\
\hline Hemorrhagic stroke & $15(17)$ \\
\hline Time since last TIA >6 months & $10(23)$ \\
\hline Time since last stroke $>6$ months & $8(21)$ \\
\hline \multicolumn{2}{|l|}{ MRI measures } \\
\hline Brain infarct & $65(72)$ \\
\hline Intraparenchymal hemorrhage & $22(24)$ \\
\hline Microbleed & $3(3)$ \\
\hline Intravascular hyperintensities & $53(59)$ \\
\hline \multicolumn{2}{|l|}{ Angiographic measures } \\
\hline Arterial narrowing or occlusion score ${ }^{c}$ & $4(2-6)$ \\
\hline Suzuki score $^{d}$ & $2(2-3)$ \\
\hline Transdural anastomosis & $21 / 70(30)$ \\
\hline \multicolumn{2}{|l|}{ SPECT perfusion measures } \\
\hline Reduced CVR & $14 / 33(42)$ \\
\hline
\end{tabular}

Table 1 Baseline demographic, angiographic, clinical, MRI, and perfusion measures (continued)

\begin{tabular}{|c|c|}
\hline & $\begin{array}{l}\text { No. (\%) or median } \\
\text { (IQR) }\end{array}$ \\
\hline $\begin{array}{l}\text { Reduced arterial steno-occlusion-related } \\
\text { perfusion decrease }\end{array}$ & $18 / 35$ (51) \\
\hline \multicolumn{2}{|c|}{$\begin{array}{l}\text { Abbreviations: CVR = cerebrovascular reserve; IQR = interquartile range; } \\
\text { MMA = moyamoya angiopathy; MMD = moyamoya disease; MMS = moya- } \\
\text { moya syndrome. } \\
\text { Percentages are computed on the entire sample of } 90 \text { patients unless } \\
\text { specified otherwise. } \\
\text { a Four individuals originated from South America }(n=2) \text { or had multiple } \\
\text { ethnic origin }(n=2) \text {. They were not considered in the statistical analysis. } \\
\text { b An Asian origin was retained for patients originating from East Asia, } \\
\text { Southeast Asia, Western Asia, Central Asia, North Asia, or South Asia. } \\
\text { cSum of arteries with either stenosis or occlusion (ranging from } 0 \text { to 8). } \\
\text { d Sixteen missing data points. }\end{array}$} \\
\hline
\end{tabular}

receiver operator characteristic curve (AUC) as a measure of discrimination. ${ }^{25}$

The level of significance was set at 0.05 (2-tailed). All analyses were performed using $\mathrm{R}$ statistical software version 3.3.2 (Rproject.org/).

\section{Data availability}

Anonymized data will be shared by request from any qualified investigator for purposes of replicating procedures and results.

\section{Results}

\section{Clinical and imaging data at baseline}

Among the 113 patients referred with possible MMA during the study period, 90 consecutive cases fulfilled the inclusion criteria and were included in the primary analysis. Seventeen patients were excluded for not meeting eligibility criteria, including $11 \mathrm{MMA}$ diagnosis not confirmed and 6 cases with previous or planned revascularization surgery. Six additional patients with a follow-up less than 1 year were excluded from the analysis. The diagnosis of MMA was confirmed by conventional angiography in 75 cases (83\%) and on magnetic resonance angiography combined to cerebral MRI in the remaining 15 participants. Among the 90 patients included in the study, $54(60 \%)$ were diagnosed with MMD and 36 (40\%) with MMS. Associated conditions identified in MMS cases included Down syndrome $(\mathrm{n}=3)$, neurofibromatosis type $1(\mathrm{n}=2)$, Alagille syndrome $(\mathrm{n}=1)$, MMA related to PRSS1 gene $(\mathrm{n}=1)$, GUCY1A3 gene $(\mathrm{n}=1)$, and BRCC3-MTCP1 genes $(\mathrm{n}=1)$, Graves disease $(\mathrm{n}=3)$, Hashimoto thyroiditis $(\mathrm{n}=2)$, antiphospholipid syndrome $(\mathrm{n}=$ $2)$, intracranial fibromuscular dysplasia $(\mathrm{n}=3)$, and cranial irradiation $(n=1)$. Sixteen patients were considered as having MMS of unknown etiology because they showed dysmorphic or 
Figure 1 Total outcome events

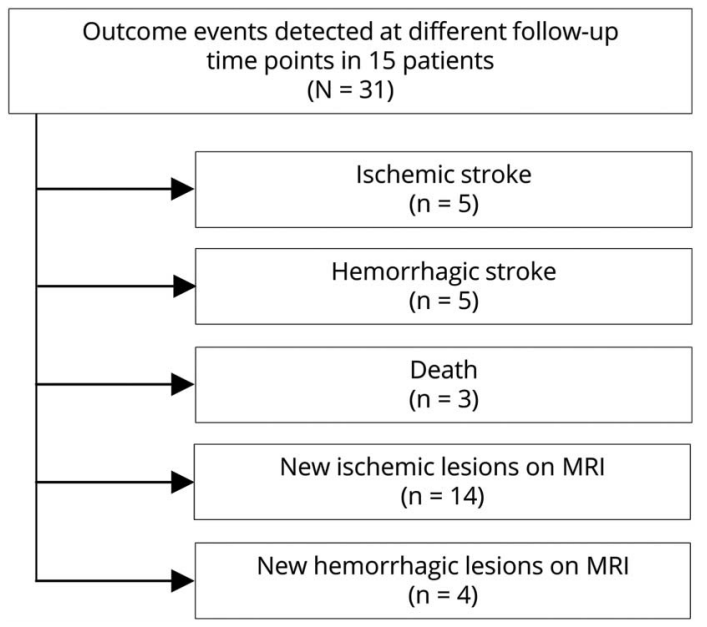

rare malformative features or they had a familial history suggesting a genetic MMS. The main demographic, clinical, and imaging characteristics of the patients included in the study are detailed in table 1 . Seventy cases (78\%) had a history of cerebrovascular events, 35 complained of recurrent headaches (39\%), 10 reported seizures (11\%), and 7 (8\%) had no previous clinical manifestations of the disease.

\section{Follow-up}

The median time to follow-up was 42.8 months (IQR 21.2-65.6 months). Ten strokes occurred in 8 of 90 patients $(9 \%)$ and were either ischemic $(n=5)$ or hemorrhagic $(n=5)$ (figure 1$)$. TIAs were reported by 14 patients (16\%) during follow-up. The mRS score increased between baseline and the last follow-up visit in 10 patients; 4 individuals became slightly disabled ( $\mathrm{mRS} 1$ or 2 ); 3 became moderately disabled ( $\mathrm{mRS} 3$ ); and 3 others died ( $\mathrm{mRS}=$ 6), always after a large intracerebral hemorrhage. Eighteen incident ischemic and hemorrhagic lesions were detected on MRI in 10 and 7 cases, respectively. At the end of the follow-up period, 15 patients (17\%) had had a stroke, evidence of ischemic or hemorrhagic lesion on MRI, or had died, accounting for a total of 31 outcome events (figure 1). As shown in figure 2, the hazard of events was relatively constant during the follow-up period. In 10 patients for whom a decision of a surgical revascularization was made (11\%), follow-up data were censored from that point.

\section{Predictors}

The results of univariate analyses of all demographic, clinical, and potential imaging predictors of clinical deterioration or cerebral tissue changes are detailed in table 2. Based on univariable analyses, 9 predictors-(1) Asian origin, (2) MMD type, (3) presence of bilateral MMA, (4) history of hypertension, (5) previous occurrence of TIA(s), (6) presence of brain infarcts on baseline MRI, (7) arterial narrowing or occlusion score $<2$ on cerebral angiography, (8) detection of arterial steno-occlusionrelated hypoperfused areas, and (9) decreased CVR on SPECT images - were related to the combination of outcome events (table 2 ). In the multivariate model, only 3 independent variables - Asian origin, a history of TIA, and reduced CVR-were retained as adding predictive information to each other based on the AIC (table 3 ).

Based on these 3 measures, 8 subsets of patients with different cumulative hazards of events were delineated, as illustrated in figure 3. The 3-year cumulative incidence of events for each of these 8 subgroups is presented in table 4 . Patients with none of these 3 predictors had an annual risk of stroke or cerebrovascular lesion of $0.5 \%$; this risk was more than doubled for patients of Asian origin or those with a history of TIAs, and was increased 10-fold when CVR was altered. When all 3 predictors were present, the annual risk was greater than $20 \%$ per year.

Internal model validation showed a Somers $\mathrm{D}$ value of $\sim 0.65$ in both models; that is, when one patient was observed to be free of events compared with another, the patient free of events was $65 \%$ more likely to have the lower of the 2 hazard ratios predicted by the model than the patient free of events was to have the higher of the 2 predicted hazard ratios. The AUC showed that the probability that the patient free of events had the lower hazard ratio approached $80 \%$ (table 3 ).

\section{Discussion}

In this largest prospective study of MMA ever performed in surgically naive adult individuals, we found that Asian

Figure 2 Observed cumulative hazard of events over time

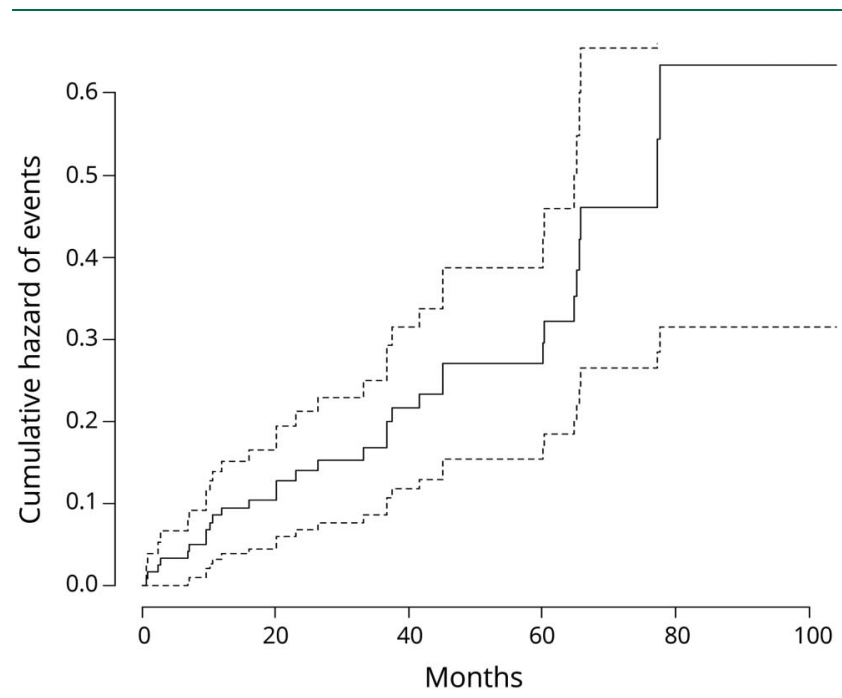

Note that the hazard of events was relatively constant during the whole follow-up period. 
Table 2 Baseline demographic, clinical, MRI, perfusion imaging, and angiographic predictors of clinical deterioration and cerebral tissue changes (univariate models)

\begin{tabular}{llc}
\hline & HR $(\mathbf{9 5} \% \mathrm{Cl})$ & $\boldsymbol{p}$ Value \\
\hline Age at first symptom $>\mathbf{3 0}$ years & $0.96(0.47-1.97)$ & 0.91 \\
\hline Age at baseline $\mathbf{7 0}$ years & $1.33(0.66-2.70)$ & 0.43 \\
\hline Female & $1.13(0.50-2.56)$ & 0.77 \\
\hline Ethnic origin & & \\
\hline European & $1.07(0.5-2.29)$ & 0.85 \\
\hline Asian & $2.70(1.09-6.68)$ & 0.03 \\
\hline Africa & $0.50(0.17-1.42)$ & 0.19 \\
\hline MMA type & 1.00 & \\
\hline MMD & $10.8(0.39-1.64)$ & 0.53 \\
\hline MMS & $2.5(0.87-7.18)$ & 0.089 \\
\hline Bilaterality & & \\
\hline
\end{tabular}

Stroke risk factors

\begin{tabular}{lll}
\hline Hypertension & $2.7(1.26-5.78)$ & 0.01 \\
\hline Hypercholesterolemia & $1.28(0.62-2.65)$ & 0.51 \\
\hline Active smoking & $1.15(0.51-2.58)$ & 0.74 \\
\hline Diabetes mellitus & $0.53(0.07-3.91)$ & 0.53 \\
\hline Alcohol consumption & $7.93(2.81-22.37)$ & $<0.0001$ \\
\hline Main clinical manifestations & & \\
\hline Positive history of TIAs & $4.75(1.77-12.74)$ & 0.002 \\
\hline Ischemic stroke & $1.09(0.54-2.21)$ & 0.81 \\
\hline Hemorrhagic stroke & $0.39(0.11-1.38)$ & 0.14 \\
\hline Time since last TIA >6 months & $1.23(0.46-3.29)$ & 0.68 \\
\hline Time since last stroke >6 months & $0.85(0.21-3.39)$ & 0.82 \\
\hline MRI measures & & \\
\hline Brain infarct & $4.15(0.99-17.39)$ & 0.052 \\
\hline Intraparenchymal hemorrhage & $1.29(0.62-2.70)$ & 0.49 \\
\hline Intravascular hyperintensities & $0.95(0.46-1.99)$ & 0.89 \\
\hline Angiographic measures & $0.22(0.03-1.67)$ & 0.14 \\
\hline Arterial narrowing or occlusion score & $0.13(0.02-0.93)$ & 0.042 \\
\hline Suzuki score >3 & $0.19(0.03-1.49)$ & 0.11 \\
\hline Transdural anastomosis & $13.64(1.06-106.81)$ & 0.013 \\
\hline SPECT measures & & \\
\hline Hypoperfusion related to ASOL & & \\
\hline Reduced CVR & & \\
\hline
\end{tabular}

Abbreviations: $\mathrm{ASOL}=$ arterial steno-occlusive lesions; $\mathrm{Cl}=$ confidence interval; $\mathrm{CVR}$ = cerebrovascular reserve; $\mathrm{MMA}$ = moyamoya angiopathy; $\mathrm{MMD}$ = moyamoya disease; $\mathrm{MMS}$ = moyamoya syndrome; $\mathrm{OR}=$ odds ratio. origin, a history of TIAs, and detection of regional alterations in cerebral hemodynamic reserve were independently associated with an increased risk of stroke or incidence of cerebral lesions over a median time of 3.6 years. Specifically, our results indicate that, when none of these 3 factors was present, the risk of clinical or cerebral lesions progression was only $0.5 \%$ per year, but exceeded $20 \%$ per year when all 3 factors were present.

In the present cohort, 3 of 90 individuals died and only $9 \%$ of cases had ischemic or hemorrhagic stroke. This frequency is much lower than that previously reported in historical cohort studies of adult MMA patients, in which only a limited number of nonoperated individuals were recruited. ${ }^{15-18}$ However, this value is close to the $10.2 \%$ incidence of strokes reported in a recent study of 49 patients that specifically examined the potential predictive value of oxygen extraction fraction over a similar time frame. ${ }^{14}$

A history of TIA(s) was associated with a 4-fold increase in the risk of stroke, death, or cerebral lesions in this study. In the general population, the occurrence of TIA(s), which in most cases result from a transient intracranial artery occlusion caused by an embolism or in situ thrombotic occlusion, represents a major risk for subsequent ischemic stroke. ${ }^{26,27}$ In MMA patients, TIAs may essentially result from a transient, but profound, decrease in blood supply downstream of chronic steno-occlusive arterial lesions when the limits of autoregulation are exceeded. ${ }^{28}$ Thus, any potential source of vasoconstriction at the cerebral level (e.g., decrease in $\mathrm{CO}_{2}$ partial pressure due to hyperventilation with crying or exertion) or reduction in blood pressure (e.g., in association with induction of anesthesia or use of antihypertensive agents) can promote the ischemic manifestations frequently observed in patients with MMA. ${ }^{29}$ A completed ischemic stroke might represent the ultimate and final consequence of this process, which could explain why TIAs, but not ischemic strokes, were associated with the incidence of stroke events in our cohort. Notably, patients with recent TIAs were not at higher risk than those with TIAs that occurred more than 6 months previously, suggesting that TIAs may remain a good predictor of stroke events over a long time frame in MMA.

In line with this interpretation, we also observed that a reduction in $\mathrm{CVR}^{30}$ caused a 4 -fold increase in the risk of clinical worsening or incidence of cerebral tissue changes. It was previously reported that the regional oxygen extraction fraction, which presumably increases at the cerebral tissue level when autoregulation is exceeded, ${ }^{31}$ does not predict stroke incidence in patients with MMA. ${ }^{14,32}$ The limited number of patients included in these studies, low event rate, rare prevalence of high oxygen extraction fraction, and large number of censored cases due to the decision to pursue revascularization surgery might explain 
Table 3 Multivariate analysis after multiple imputation of missing data and implementation of a backward selection procedure

\begin{tabular}{lllll}
\hline Significant predictors & HR $(95 \% \mathrm{Cl})$ & $\boldsymbol{p}$ Value & Validation tests & Values \\
\hline Asian & $2.63(1.00-6.94)$ & 0.051 & Somers D & 0.640 \\
\hline TIA & $4.18(1.37-12.75)$ & 0.012 & $\mathrm{R}^{2}$ & 0.340 \\
\hline Reduced CVR & $4.40(1.20-16.10)$ & 0.026 & $60-m o n t h$ AUC \\
\hline
\end{tabular}

Abbreviations: $\mathrm{AUC}=$ area under the time-dependent receiver operator characteristic curve; $\mathrm{Cl}=$ confidence interval; $\mathrm{CVR}=$ cerebrovascular reserve; $\mathrm{HR}=$ hazard ratio.

these negative results. In the present study, a decrease in CVR had a predictive value independently of TIAs, which are also presumably related to hemodynamic alterations. This suggests that alterations in CVR might be detected prior to or in the absence of any transient ischemic clinical manifestations. Alternatively, TIAs might also result from cerebral tissue dysfunction in areas distinct from the location whereas CVR decrease was detected by SPECTbased measurements of CBF. Most importantly, the results obtained in this cohort also show that the combination of TIA(s) and a reduction in CVR considerably increases the risk of clinical worsening or the incidence of cerebral lesions, which were estimated to be greater than $10 \%$ per year at the individual level. Taken together, these findings emphasize that the presence of regional CVR alterations, which can, but not necessarily do, translate into transient focal symptoms, is of the utmost importance for evaluating the risk of clinical or cerebral lesion progression in MMA.
The number of outcome events was too low to evaluate whether a history of TIAs or a decrease in CVR has the same predictive value for ischemic and hemorrhagic events. However, accumulating evidence suggests that hemodynamic failure at the cerebral level promotes not only ischemic but also hemorrhagic lesions. In particular, it has been found that long-term hemodynamic stress to collateral vessels is capable of altering vascular wall structure, leading to cerebral hemorrhage. ${ }^{1,33}$ In keeping with this, cerebral revascularization after extracranial-intracranial bypass surgery, which decreases this phenomenon, ${ }^{34}$ prevents not only ischemic but also hemorrhagic manifestations of the disease. $^{35}$

Asian origin was also independently predictive of the incidence of stroke, cerebral lesions, or death in our MMA patient cohort, though its prognostic value was decreased in the multivariable models, suggesting some levels of confounding. Nevertheless, this was in agreement with

Figure 3 Cumulative hazard of events over time predicted by the model

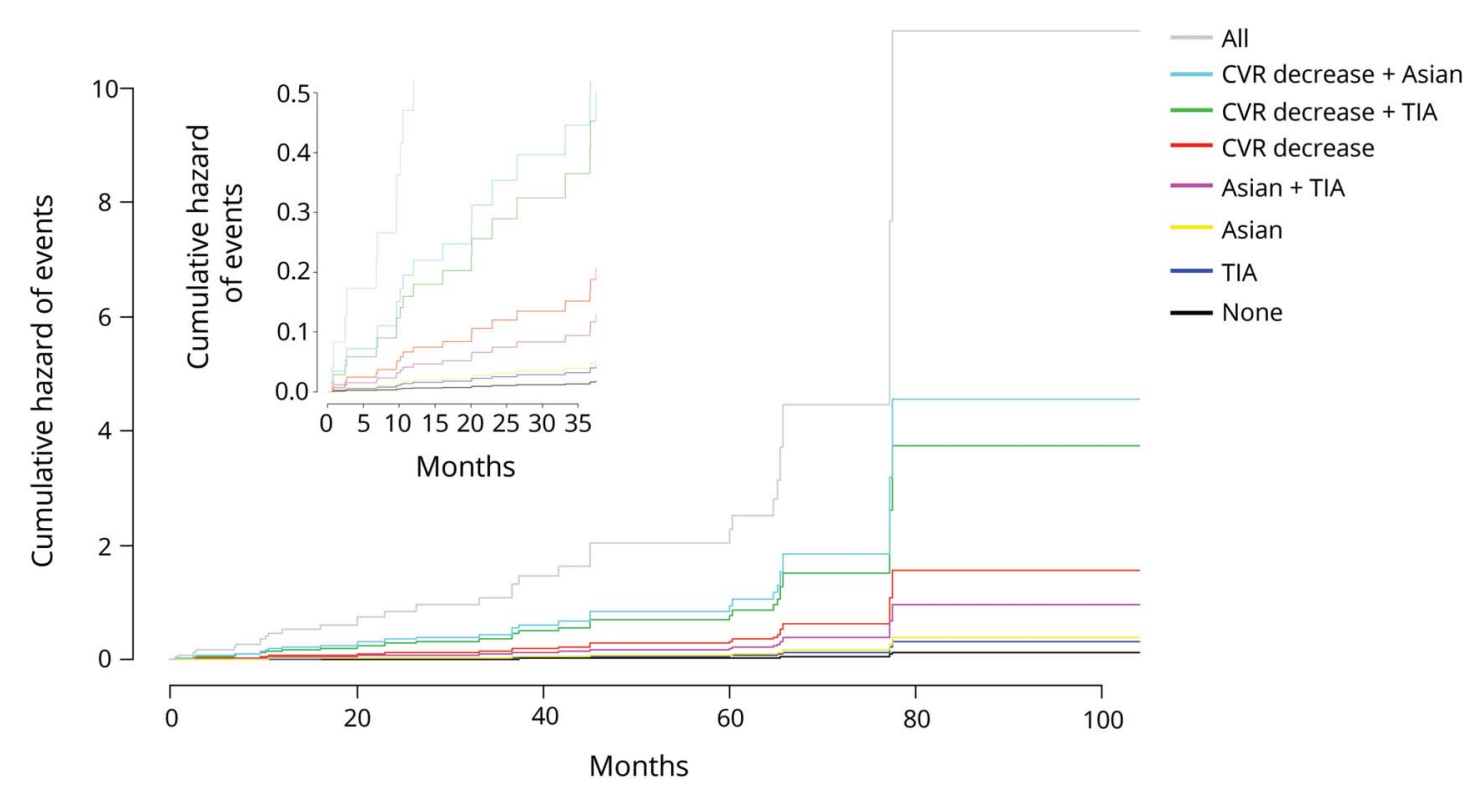

A zoom of the cumulative hazard of events during the 35 first months of follow-up is shown in the center of the panel. CVR = cerebrovascular reserve. 
Table 4 Estimated risk event at 3 years, according to multiple combinations of predictive factors (from smallest to largest values)

\begin{tabular}{ll}
\hline & Risk event at $\mathbf{3}$ years, \% \\
\hline No predictive factor & 1.5 \\
\hline Previous TIAs & 3.5 \\
\hline Asian origin & 4.3 \\
\hline Asian origin and previous TIAs & 10 \\
\hline Reduced CVR & 15.6 \\
\hline Reduced CVR and previous TIAs & 33.5 \\
\hline Asian origin and reduced CVR & 39.2 \\
\hline All predictive factors & 69.9 \\
\hline
\end{tabular}

Abbreviation: CVR = cerebrovascular reserve.

previous findings. Indeed, in 2 large MMA series, it was previously reported that ethnicity is an important determinant of prognosis. ${ }^{13}$ Recently, the $\mathrm{R} 4810 \mathrm{~K}$ variant of ring finger protein 213 (RNF213) was found to be strongly associated with MMD in both Japanese and Korean patients, and to a much lesser degree in Chinese patients. ${ }^{36}$ This variant is not associated with MMD in Caucasian individuals. ${ }^{37}$ Additional investigations are needed to determine whether the worse prognosis associated with an Asian origin is related to genetic differences that influence the progression of cerebral arterial lesions in MMA or to another cause.

Female sex and Suzuki score were not found independently associated with an increased risk of stroke or incidence of cerebral lesions. These results contrast with what previous studies suggested. ${ }^{38-40}$ This may be due to the cohort size and to a lack of power.

Specific strengths of this study include the prospective design of standardized data collection for this rare condition in a European referral center, the relatively large sample size and long evaluation period without a surgical revascularization decision, the centralized data management, and strong internal validation of the prediction model.

There are also several potential limitations. The recruitment period was long, and intervals between followup visits were variable owing to multiple logistical constraints. Moreover, the number of events was relatively low and variable at the individual level. However, we used the Andersen-Gill counting process model, which allows consideration of both multiple events within subjects and the discontinuous structure of the data. To increase the power to detect predictors in such a cohort, we also selected patients independently of their MMA etiologic subtypes and considered both clinical and imaging events as outcomes. Etiologic heterogeneity did not seem to have a major role in predicting outcomes in our dataset, but cannot be excluded. Hemodynamic status evaluation using SPECT was not performed in the whole cohort. We used, because of this specific limitation, a model selection including MICE of missing data. In this study, we retained an Asian origin not only for patients originating from East Asia, but also for patients originating from other subregions of this continent. Additional studies would be needed to confirm these results in patients originating from East Asia. A larger sample would also be needed to confirm these results based only on clinical manifestations. In addition, although an internal validation was performed, our prediction model was not externally validated using independently collected data from a different source. Finally, participants with a history of surgical revascularization were not included in this study. This selection criterion might have underestimated the risk of events, since only patients with a less severe condition would have been selected. However, only 6/113 (5.3\%) patients screened for inclusion were ultimately excluded because of planned or previous revascularization surgery, and most of the enrolled cases were symptomatic and had a history of TIA(s), or ischemic or hemorrhagic stroke at baseline.

This study clearly demonstrates that a simple combination of demographic, clinical, and imaging markers may aid in predicting the risk of clinical worsening and cerebral tissue changes in adult patients with MMA. The information provided by these results is important for improving the management of MMA in adult patients, particularly regarding therapeutic decisions, as well as for designing future therapeutic trials in this rare condition.

\section{Acknowledgment}

The authors thank the patients and their families; S. Hello for involvement in the practical organization of the study; A. Taleb and N. Gastellier for technical support; and E. Jouvent and C. Stapf for contributions.

\section{Study funding}

The study was funded by the Tanguy moyamoya patient association. The funders of the study had no role in the design, data collection, data analysis, data interpretation, or writing of the report. The corresponding author had full access to all the data in the study and had final responsibility for the decision to submit for publication.

\section{Disclosure}

The authors report no disclosures relevant to the manuscript. Go to Neurology.org/N for full disclosures.

\section{Publication history}

Received by Neurology August 27, 2018. Accepted in final form March 11, 2019. 
Appendix Authors

\begin{tabular}{|c|c|c|c|}
\hline Name & Location & Role & Contribution \\
\hline $\begin{array}{l}\text { Dominique } \\
\text { Hervé, MD }\end{array}$ & $\begin{array}{l}\text { University } \\
\text { Hospital } \\
\text { Lariboisière, Paris, } \\
\text { France }\end{array}$ & Author & $\begin{array}{l}\text { Contributed to the } \\
\text { protocol development, } \\
\text { study design and } \\
\text { concept, conduct, data } \\
\text { acquisition, and } \\
\text { coordination, data } \\
\text { interpretation, writing } \\
\text { and reviewing of the } \\
\text { report }\end{array}$ \\
\hline
\end{tabular}

\begin{tabular}{|c|c|c|c|}
\hline $\begin{array}{l}\text { Nathanaelle } \\
\text { Ibos-Augé, } \\
\text { MD }\end{array}$ & $\begin{array}{l}\text { University } \\
\text { Hospital } \\
\text { Lariboisière, Paris, } \\
\text { France }\end{array}$ & Author & $\begin{array}{l}\text { Involved in data } \\
\text { interpretation and } \\
\text { writing the first draft }\end{array}$ \\
\hline $\begin{array}{l}\text { Lionel } \\
\text { Calvière, MD }\end{array}$ & $\begin{array}{l}\text { University } \\
\text { Hospital Pierre- } \\
\text { Paul-Riquet, } \\
\text { Toulouse, France }\end{array}$ & Author & $\begin{array}{l}\text { Involved in data } \\
\text { acquisition and revising } \\
\text { the report }\end{array}$ \\
\hline $\begin{array}{l}\text { Christina } \\
\text { Rogan, MSc }\end{array}$ & $\begin{array}{l}\text { University } \\
\text { Hospital } \\
\text { Lariboisière, Paris, } \\
\text { France }\end{array}$ & Author & $\begin{array}{l}\text { Involved in study } \\
\text { conduct and data } \\
\text { acquisition }\end{array}$ \\
\hline $\begin{array}{l}\text { Marc } \\
\text { Antoine } \\
\text { Labeyrie, } \\
\text { MD }\end{array}$ & $\begin{array}{l}\text { University } \\
\text { Hospital } \\
\text { Lariboisière, Paris, } \\
\text { France }\end{array}$ & Author & $\begin{array}{l}\text { Involved in data } \\
\text { acquisition and revising } \\
\text { the report }\end{array}$ \\
\hline $\begin{array}{l}\text { Jean Pierre } \\
\text { Guichard, } \\
\text { MD }\end{array}$ & $\begin{array}{l}\text { University } \\
\text { Hospital } \\
\text { Lariboisière, Paris, } \\
\text { France }\end{array}$ & Author & $\begin{array}{l}\text { Involved in data } \\
\text { acquisition and revising } \\
\text { the report }\end{array}$ \\
\hline $\begin{array}{l}\text { Ophélia } \\
\text { Godin, PhD }\end{array}$ & $\begin{array}{l}\text { University } \\
\text { Hospital }\end{array}$ & Author & $\begin{array}{l}\text { Designed and executed } \\
\text { the statistical analysis }\end{array}$ \\
\hline
\end{tabular}

\begin{tabular}{|c|c|c|c|}
\hline GodIn, PhD & $\begin{array}{l}\text { Hospital } \\
\text { Lariboisière, Paris, } \\
\text { France }\end{array}$ & & the statistical analysis \\
\hline $\begin{array}{l}\text { Manoelle } \\
\text { Kossorotoff, } \\
\text { MD, PhD }\end{array}$ & $\begin{array}{l}\text { University } \\
\text { Hospital Necker } \\
\text { Enfants Malades, } \\
\text { Paris, France }\end{array}$ & Author & $\begin{array}{l}\text { Involved in study } \\
\text { conduct, data } \\
\text { acquisition, revising the } \\
\text { report }\end{array}$ \\
\hline $\begin{array}{l}\text { Marie Odile } \\
\text { Habert, MD }\end{array}$ & $\begin{array}{l}\text { University } \\
\text { Hospital Pitié } \\
\text { Salpêtrière, Paris, } \\
\text { France }\end{array}$ & Author & $\begin{array}{l}\text { Involved in study } \\
\text { conduct, data } \\
\text { acquisition, revising the } \\
\text { report }\end{array}$ \\
\hline $\begin{array}{l}\text { Elisabeth } \\
\text { Tournier } \\
\text { Lasserve, } \\
\text { MD }\end{array}$ & $\begin{array}{l}\text { University } \\
\text { Hospital } \\
\text { Lariboisière, Paris, } \\
\text { France }\end{array}$ & Author & $\begin{array}{l}\text { Involved in data } \\
\text { interpretation and } \\
\text { revising the report } \\
\text { critically }\end{array}$ \\
\hline $\begin{array}{l}\text { Sylvie } \\
\text { Chevret, MD, } \\
\text { PhD }\end{array}$ & $\begin{array}{l}\text { University } \\
\text { Hospital Saint- } \\
\text { Louis, Paris, } \\
\text { France }\end{array}$ & Author & $\begin{array}{l}\text { Designed and executed } \\
\text { the statistical analysis, } \\
\text { wrote the first draft of } \\
\text { the statistical analysis, } \\
\text { reviewed the report }\end{array}$ \\
\hline $\begin{array}{l}\text { Hugues } \\
\text { Chabriat, } \\
\text { MD, PhD }\end{array}$ & $\begin{array}{l}\text { University } \\
\text { Hospital } \\
\text { Lariboisière, Paris, } \\
\text { France }\end{array}$ & Author & $\begin{array}{l}\text { Involved in study design } \\
\text { and concept, data } \\
\text { interpretation, critical } \\
\text { revision, reviewing the } \\
\text { report }\end{array}$ \\
\hline
\end{tabular}

\section{References}

1. Kuroda S, Houkin K. Moyamoya disease: current concepts and future perspectives. Lancet Neurol 2008;7:1056-1066.

2. Tho-Calvi SC, Thompson D, Saunders D, et al. Clinical features, course, and outcomes of a UK cohort of pediatric moyamoya. Neurology 2018;90:e763-e770.

3. Blauwblomme T, Mathon B, Naggara O, et al. Long-term outcome after multiple burr hole surgery in children with moyamoya angiopathy: a single-center experience in 108 hemispheres. Neurosurgery 2017;80:950-956.
4. Liu XJ, Zhang D, Wang S, et al. Clinical features and long-term outcomes of moyamoya disease: a single-center experience with 528 cases in China. J Neurosurg 2015; 122:392-399.

5. Kazumata $\mathrm{K}$, Ito $\mathrm{M}$, Tokairin $\mathrm{K}$, et al. The frequency of postoperative stroke in moyamoya disease following combined revascularization: a single-university series and systematic review. J Neurosurg 2014;121:432-440.

6. Kim SK, Cho BK, Phi JH, et al. Pediatric moyamoya disease: an analysis of 410 consecutive cases. Ann Neurol 2010;68:92-101.

7. Guzman R, Lee M, Achrol A, et al. Clinical outcome after 450 revascularization procedures for moyamoya disease: clinical article. J Neurosurg 2009;111: 927-935.

8. Scott RM, Smith JL, Robertson RL, Madsen JR, Soriano SG, Rockoff MA. Long-term outcome in children with moyamoya syndrome after cranial revascularization by pial synangiosis. J Neurosurg 2004;100:142-149.

9. Mukawa M, Nariai T, Matsushima Y, et al. Long-term follow-up of surgically treated juvenile patients with moyamoya disease. J Neurosurg Pediatr 2012;10 451-456.

10. Khan N, Schuknecht B, Boltshauser E, et al. Moyamoya disease and moyamoya syndrome: experience in Europe; choice of revascularisation procedures. Acta Neurochir 2003; 145:1061-1071.

11. Acker G, Fekonja L, Vajkoczy P. Surgical management of moyamoya disease. Stroke 2018;49:476-482.

12. Jeon JP, Kim JE, Cho WS, Bang JS, Son YJ, Oh CW. Meta-analysis of the surgical outcomes of symptomatic moyamoya disease in adults. J Neurosurg 2018;128: 793-799.

13. Ganesan V, Smith ER. Moyamoya: defining current knowledge gaps. Dev Med Child Neurol 2015;57:786-787.

14. Derdeyn CP, Zipfel GJ, Zazulia AR, et al. Baseline hemodynamic impairment and future stroke risk in adult idiopathic moyamoya phenomenon: results of a prospective natural history study. Stroke 2017;48:894-899.

15. Funaki T, Takahashi JC, Houkin K, et al. High rebleeding risk associated with choroidal collateral vessels in hemorrhagic moyamoya disease: analysis of a nonsurgical cohort in the Japan Adult Moyamoya Trial. J Neurosurg 2018:1-8.

16. Choi JU, Kim DS, Kim EY, Lee KC. Natural history of moyamoya disease: comparison of activity of daily living in surgery and non surgery groups. Clin Neurol Neurosurg 1997;99(suppl 2):S11-S18.

17. Kuroda S, Hashimoto N, Yoshimoto T, Iwasaki Y. Radiological findings, clinical course, and outcome in asymptomatic moyamoya disease: results of multicenter survey in Japan. Stroke 2007;38:1430-1435.

18. Liu X, Zhang D, Shuo W, Zhao Y, Wang R, Zhao J. Long term outcome after conservative and surgical treatment of haemorrhagic moyamoya disease. J Neurol Neurosurg Psychiatry 2013;84:258-265.

19. Miyoshi K, Chida K, Kobayashi M, et al. Two-year clinical, cerebral hemodynamic, and cognitive outcomes of adult patients undergoing medication alone for symptomatically Ischemic Moyamoya disease without cerebral misery perfusion: a prospective cohort study. Neurosurgery 2018;84:1233-1241.

20. Vandenbroucke JP, von Elm E, Altman DG, et al. Strengthening the reporting of observational studies in epidemiology (STROBE): explanation and elaboration. Ann Intern Med 2007;147:W163-W194.

21. Research Committee on the Pathology and Treatment of Spontaneous Occlusion of the Circle of Willis; Health Labour Sciences Research Grant for Research on Measures for Infractable Diseases. Guidelines for diagnosis and treatment of moyamoya disease (spontaneous occlusion of the Circle of Willis). Neurol Med Chir 2012;52:245-266.

22. ICoH. ICH Tripartite Guideline for Good Clinical Practices E6 (R1), June 10, 1996. Available at: ich.org/fileadmin/Public_Web_Site/ICH_Products/Guidelines/Efficacy/E6/E6_R1_Guideline.pdf. Accessed January 19, 2017.

23. Ling Y, De Guio F, Jouvent E, et al. Clinical correlates of longitudinal MRI changes in CADASIL. J Cereb Blood Flow Metab Epub 2018 Feb 5.

24. Andersen PK, Gill RD. Cox's regression model for counting processes: a large sample study. Ann Stat 1982;10:1100-1120.

25. Blanche P, Dartigues JF, Jacqmin-Gadda H. Estimating and comparing timedependent areas under receiver operating characteristic curves for censored event times with competing risks. Stat Med 2013;32:5381-5397.

26. Lavallee P, Amarenco P. [Transient ischemic attacks.] Presse Med 2007;36: 134-141

27. Lavallée P, Amarenco P. TIA clinic: a major advance in management of transient ischemic attacks. Front Neurol Neurosci 2014;33:30-40.

28. Lee JK, Williams M, Reyes M, Ahn ES. Cerebrovascular blood pressure autoregulation monitoring and postoperative transient ischemic attack in pediatric moyamoya vasculopathy. Paediatr Anaesth 2018;28:94-102.

29. Scott RM, Smith ER. Moyamoya disease and moyamoya syndrome. N Engl J Med 2009;360:1226-1237.

30. Tsivgoulis G, Alexandrov AV. Cerebral hemodynamics in acute stroke: pathophysiology and clinical implications. J Vasc Interv Neurol 2008;1:65-69.

31. Lee M, Zaharchuk G, Guzman R, Achrol A, Bell-Stephens T, Steinberg GK. Quantitative hemodynamic studies in moyamoya disease: a review. Neurosurg Focus 2009 26:E5

32. Grubb RL Jr., Derdeyn CP, Fritsch SM, et al. Importance of hemodynamic factors in the prognosis of symptomatic carotid occlusion. JAMA 1998;280 1055-1060.

33. Takahashi JC, Miyamoto S. Moyamoya disease: recent progress and outlook. Neurol Med Chir 2010;50:824-832. 
34. Houkin K, Kamiyama H, Abe H, Takahashi A, Kuroda S. Surgical therapy for adult moyamoya disease: can surgical revascularization prevent the recurrence of intracerebral hemorrhage? Stroke 1996;27:1342-1346.

35. Miyamoto S, Yoshimoto T, Hashimoto N, et al. Effects of extracranial-intracranial bypass for patients with hemorrhagic moyamoya disease: results of the Japan Adult Moyamoya Trial. Stroke 2014;45:1415-1421.

36. Liu W, Morito D, Takashima S, et al. Identification of RNF213 as a susceptibility gene for moyamoya disease and its possible role in vascular development. PLoS One 2011; 6:e22542.
37. Liu W, Senevirathna ST, Hitomi T, et al. Genomewide association study identifies no major founder variant in Caucasian moyamoya disease. J Genet 2013;92:605-609.

38. Gross BA, Du R. The natural history of moyamoya in a North American adult cohort. J Clin Neurosci 2013;20:44-48.

39. Kuroda S, Ishikawa T, Houkin K, Nanba R, Hokari M, Iwasaki Y. Incidence and clinical features of disease progression in adult moyamoya disease. Stroke 2005;36: 2148-2153.

40. Zhao M, Deng X, Zhang D, et al. Risk factors for and outcomes of postoperative complications in adult patients with moyamoya disease. J Neurosurg 2018:1-12. 


\section{Neurology}

\section{Predictors of clinical or cerebral lesion progression in adult moyamoya angiopathy}

Dominique Hervé, Nathanaelle Ibos-Augé, Lionel Calvière, et al.

Neurology 2019;93;e388-e397 Published Online before print June 25, 2019

DOI 10.1212/WNL.0000000000007819

This information is current as of June 25, 2019

Updated Information \&
Services

References

Subspecialty Collections

Permissions \& Licensing

Reprints including high resolution figures, can be found at:

http://n.neurology.org/content/93/4/e388.full

This article cites 36 articles, 8 of which you can access for free at: http://n.neurology.org/content/93/4/e388.full\#ref-list-1

This article, along with others on similar topics, appears in the following collection(s):

Cohort studies

http://n.neurology.org/cgi/collection/cohort_studies

Other cerebrovascular disease/ Stroke

http://n.neurology.org/cgi/collection/other_cerebrovascular_disease_s troke

Prognosis

http://n.neurology.org/cgi/collection/prognosis

SPECT

http://n.neurology.org/cgi/collection/spect

Information about reproducing this article in parts (figures,tables) or in its entirety can be found online at:

http://www.neurology.org/about/about_the_journal\#permissions

Information about ordering reprints can be found online:

http://n.neurology.org/subscribers/advertise

Neurology ${ }^{\circledR}$ is the official journal of the American Academy of Neurology. Published continuously since 1951, it is now a weekly with 48 issues per year. Copyright Copyright ( 2019 The Author(s). Published by Wolters Kluwer Health, Inc. on behalf of the American Academy of Neurology.. All rights reserved. Print ISSN: 0028-3878. Online ISSN: 1526-632X.

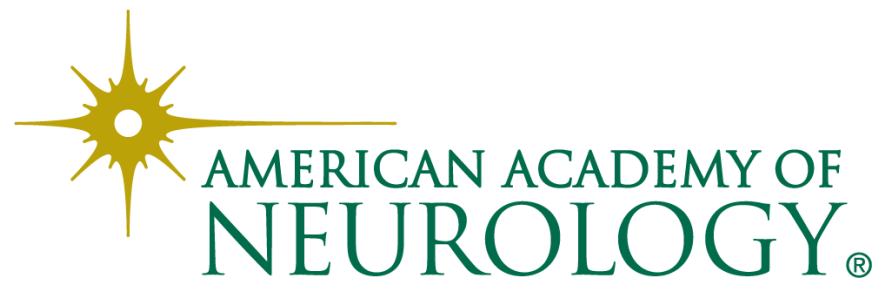

